\title{
The Impact of the Power Distribution Structure in the Family and Domestic Violence against Women
}

\author{
Mahmoud $\mathrm{Y}^{1 *}$, Behzad $\mathrm{H}^{2}$ and Hadis $\mathrm{E}^{3}$ \\ ${ }^{1}$ Department of Sociology, Shoushtar Branch, Islamic Azad University, Shoushtar, Iran \\ ${ }^{2}$ Department of Sociology, Shiraz University, Iran \\ ${ }^{3}$ Department of Sociology, Chamran University of Ahwaz, Iran
}

*Corresponding author: Mahmoud Yaghoubidoust, Department of Sociology, Shoushtar Branch, Islamic Azad University, Shoushtar, Iran, Email: M_4162004@yahoo.com

\begin{abstract}
The present paper has been written by the aim of investigating relationship Power Distribution Structure in the Family and Domestic Violence against Women of Isfahan. The theoretical frame of this thesis has been taken from the Feminism, particular Radical Feminism, Resource theory, conflict theory. According this theoretical frame specially Radical Feminism, the variables such as Socioeconomic Status, the power structure, way of exertion power have been taken as some factors effecting on the domestic violence married women. The data of research has been collected by survey from a sample made of a volume of 200 people taken from the population of married women of Isfahan by a multi-step selected cluster sampling. The results of multiple regression show that independents variables account for approximately $0 / 73$ percent of the variance of domestic violence against married women.
\end{abstract}

Keywords: Domestic Violence; Power Structure in Family; Way of Exertion Power

\section{Introduction}

The women are considered to be the most important player of the protecting-emotional director of managing cultural, economical and social circumstances in the family-members' life. Family is the home and society in which how to distribute and also how to impose power in the formation and growth of persons' characters, children's sociability, self-confidence and cohesiveness of its member, even the sense of consent, happiness and loneliness, strangeness in matrimony relationship are influenced too so when there is a problem in home, it will surely exerts and disorders in the fulfilling the functions of family. It causes some obstacles in which a woman could play a desirable role as a mother or spouse. Domestic violence is the violence that took place in the private places and it mainly happens among people who are tied due to closeness hematic and legal ties with each 


\section{Medical Journal of Clinical Trials \& Case Studies}

other. But violence in the family aspect against women isn't something new. But women's protection in the lieu of this issue is as a social obligatory problem.

Feminist's model considers the violence as a policy of possession and power based on sex. To feminists, matrimony life is so well-structured that husbands have more power and authority than wives and men had been the sole bread-winner and women had been in charge of keeping the children and household and lack the power of complaining in comparison to their husbands. As they see the difference and priority between men and women are neither natural nor functional but consist of a social structure and preserve the power of men in the family and society. Dobash RE and Dobash RD believe that women in the patriarchal system by being exerted physical violence and organically they stay in an inferior and lower condition. To their idea, the reason why women are considered to powerless in the family relationship is to lower and look-down on the women's productive and reproductive efforts society and family and also to praise men's ability in the relationship between husbands and wives. These two elements cause women have less power than men in the family - to the extent that men's inspections over women activities start - and for this problem they use various kinds of violence over women.

For more than a decade, the phenomenon of domestic violence in Iran has been at the center of attention Scholars and various academic and non-academic groups. Both now, a collection of research on domestic violence with an emphasis on violent husbands are against women in Iran. But, due to the inconsistency in the results are not interested in the subject by studying these reviews. It does not just about understand the factors that impact violence, but it's likely to be confusing.

In Human Development Indicators that have several indicators and according to the 2012 Gender Gap Report of the World Economic Forum from 135 countries, Iran ranked 127th on inequality between men and women. The rank of Iran in this report - which is the most credible report on inequality between men and women - has been generated by the World Economic Forum since 2006 (ie six years) - shows that over the past six years, Iran has fluctuated between the fourth to the fourteenth with the largest gap And gender inequality has fluctuated. This means Iran has a lower ranking in the countries such as Mali, Morocco, Saudi Arabia, Côte d'Ivoire, Chad and Syria. Thus, in the structure of the family in Iranian society, the patriarchal cultural norms that subjugate women to men, both morally and culturally, acknowledge the husband's violence against women. And this is the main issue of this research.

\section{Research Hypothesis}

- It seems that there is a significant and meaningful relation between power structure of the family and physical, sexual and economical violence against women.

- It seems that there is a significant and meaningful relation between women's education and economics, sexual and physical violence against them.

- It seems that there is a relation between socioeconomical position and sexual, physical and economic violence against women.

- It seems that there is a significant and meaningful relation between stereotypical sexual beliefs and economic, sexual and physical violence against women.

\section{Theories of the Research}

Bludvolfe's studies are known as Resource Theory. This theory states that when a person is in a condition with adequate and excessive resource, he is most likely to use violence strategy [1]. For instance, when one wants to impose his power on the others, but has a low-level resource (like education, occupation, income and skills) he resorts to violence to maintain his own position.

The feminist view to the difference between the two sexes as a result of the socialization and conditional Knows gender and believes that with boys and girls it is almost from the moment of birth in different ways Been treated. Sex is the handiwork of the community and the roles that man and woman play in society are not the product of the algebra of their nature. In other words, if all the features of each gender, which can be explained on the basis of education and external conditions, are different, then the differences that remain may be natural.

So William Good was the first one who used Bludvolfe's power resource theory to clarify men's violence against women. To his idea, all of social systems depend on force and power. Violence and threat are required to organize the social system of which family is also a part. When one has more available resources, his ability to use power increases, thus he is hardly likely to resort to violence. Gelez, in 1987, in his researches came to the conclusion that those men who are inferior to their wives social status, suffer from frustration and confusion. Since violence is the last resource of power to accomplish 


\section{Medical Journal of Clinical Trials \& Case Studies}

one's dominance, he resorts to it. In the case that men consider women's authority as menace to their manliness and to prove their existence, they use violence. In the power-structure-subject, this category includes three levels and each level has different parts [2]. 1. Power Area (economical affairs, social relations, children's upbringing) 2. Power Structure (symmetrical and asymmetrical) 3. Power-using-method (convincing or forcing) (Sabouri).

Behavior is taught through two ways in Bandura's social learning theory, either through rewarding (instrumental learning) or through aware or random observation of other people's behavior (modeling). So, the children who learn in any way to be violent may continue the learned pattern in adulthood. Also, Bandura points out to the involvement of underlying circumstances like population density, pollution, etc. in the emergence of violence in order to explain the role of families in abuse of children [3].

The idea that we use as the theoretical frame consists of feminist contrast, Bandura's social learning theory and resource theory.

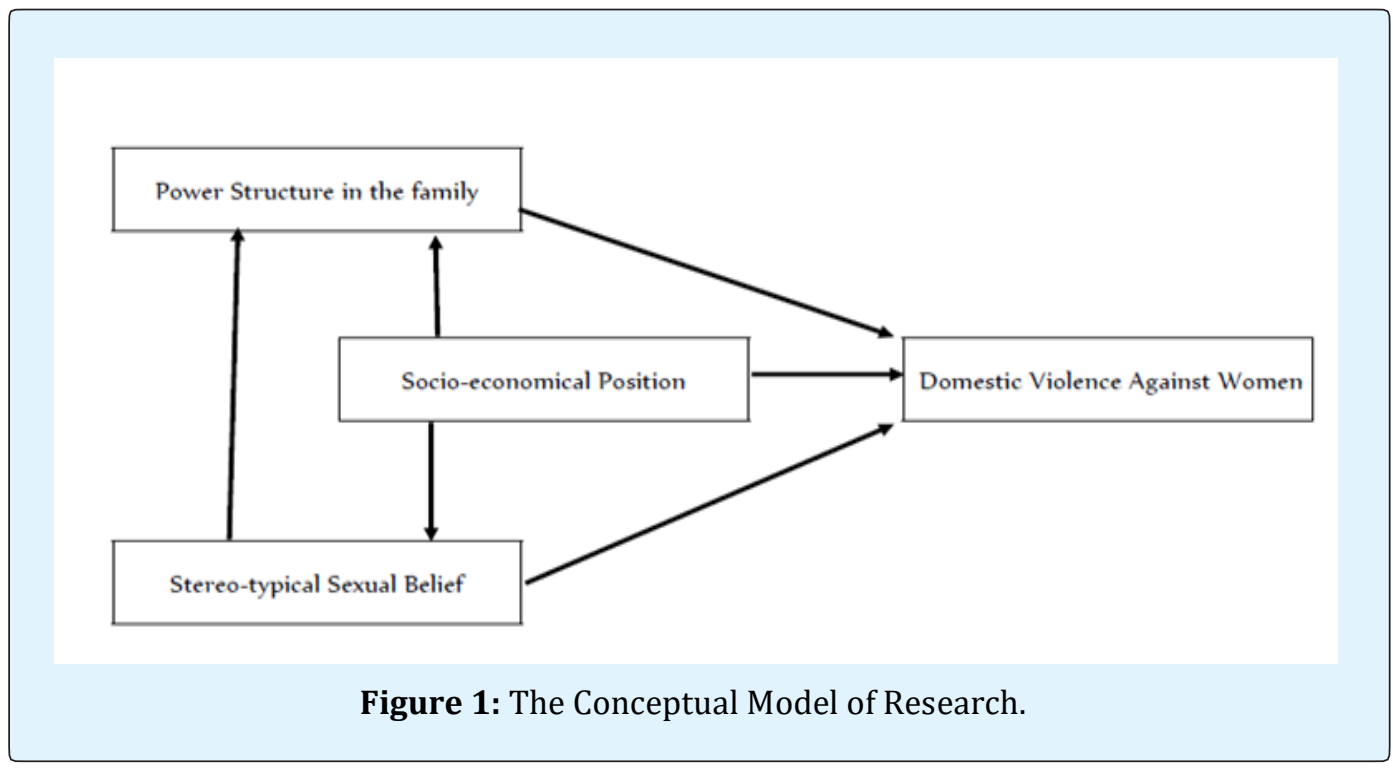

\section{Research Methodology}

This research has been carried out through traversal method and by the use of questionnaires in the city of Isfahan. The population of women of the range 18-70 is 619,794 people Isfahan. The statistical society is formed by the women of the least age of 18 . The sample volume is 200 families which have been calculated through Cochrane's Formula. This number of students have been chosen through the cluster sampling method out of different areas of the city and been given the questionnaire at random. Items have been designed through Likert's spectrum and other ones to examine every variable of this research, and the required data have been collected by the use of questionnaire technique. To measure the validity of the questions, 50 questionnaires were completed by the sample at first, and the validity coefficient was calculated through Cronbach's Alpha so that to clarify the compatibility of the items. Once the questionnaires were completed by the respondents, the data were processed at two levels of descriptive statistics and inferential statistics by the use of the software SPSS. The statistical indicators of mean, standard deviation, Pearson's correlation, and regression analysis have been used to analyze data.

\section{Tools of Evaluating the Research}

The questionnaire of observing and experiencing parental violence in childhood: This questionnaire has 40 items and made it to measure observation and experience of violence in childhood. 13 items of this questionnaire are on mental violence (sample question: Which has happened in your childhood? Cursing, Sulking, debunking your efforts, or humiliating you in front of others); 24 items are on physical violence (sample question: Which has happened in your childhood? Pushing, hitting, squeezing the throat, pulling the hair, and kicking); 3 


\section{Medical Journal of Clinical Trials \& Case Studies}

items are on witnessing or being a victim of violence (sample question: Have you witnessed your parents fighting? Have you been violated?). The answer spectrum to this questionnaire is from many to nothing in one scale of Likert's spectrum. This questionnaire has been executed in the scale of conflict tactics in one group consisting of 50 couples. The correlation between the results of the questionnaire and the above scale has been obtained as 0.81, which indicates the convergent reliability of the familial violence questionnaire.

\section{Power Measurement Tool}

Operational definition: In the forthcoming research, the combination of three indicators of power generation, the realm of power and the method of exercising power was obtained. The purpose of building power, the pattern of cooperation between husband and wife are doing homework and making decisions in different areas. The realm of related power with power in decision making between husband and wife in three areas of economic, social and birth determination and the method of exercising power are related to measuring the amount of husband making in the way of exercising power with wife. In the questionnaire used by the researcher, the grade of the total power structure in the family of Answers to Questions 10 through 15, which included a total of 40 items. The least the score is 20 and the highest score is 200, which indicates the high power of women in Family decisions are made and vice versa.

\section{Research Findings}

To inspect the relations among research variables (power structure in family, patriarchy view, sexual stereotypical belief, socio-economical position and women's education) we put all of the variables separately in test with the dependent variable -the domestic violence against women-, and the results are brought forth for discussion as following:

In Table 1 the results of Pearson's correlation ratio test between research variables and domestic violence against women are illustrated.

\begin{tabular}{|c|c|c|}
\hline Variables Names & Person's Correlation Ratio & Meaningful Leave \\
\hline Power structure in the family and physical violence & 0.718 & 0 \\
\hline Power structure in the family and sexual violence & 0.63 & 0 \\
\hline Power structure in the family and eco-nomical violence & 0.808 & 0 \\
\hline Stereo-typical sexual belief and physical violence & 0.67 & 0 \\
\hline Stereo-typical sexual belief and sexual violence & 0.584 & 0 \\
\hline Stereo-typical sexual belief and economical violence & 0.76 & 0 \\
\hline Socio-economical position and physical violence & -0.283 & 0 \\
\hline Socio-economical position and sexual violence & -0.3 & 0 \\
\hline Social-economical position and economical violence & -0.0256 & 0 \\
\hline
\end{tabular}

Table 1: Pearson's correlation ratio test between research variables and domestic violence against women.

As you can see in the above table there is a connection between all the independent variables and dependent variable. Power structure in the family, patriarchy view and stereo-typical sexual belief has direct and positive connection with high correlation ratio of domestic violence in its three aspects (physical, sexual and economic) against women. That is to say, the more asymmetrical the power structure in the family is and the more intense stereo-typical sexual belief gets, the more violence will be against women. As well, if the women have a higher socio-economical position, they will encounter lower domestic violence.

\begin{tabular}{|c|c|c|c|c|c|}
\hline Change Sources & Freedom Rate & Squares Total & Squares Average & F Quantity & Meaningful Leave \\
\hline Inter-group & 6 & 10275.513 & 1712.586 & \multirow{2}{*}{5} & \multirow{2}{*}{0} \\
\cline { 1 - 4 } Intra-group & 192 & 58488.447 & 304.627 & \\
\hline Total & 198 & 68763.96 & & & \\
\hline
\end{tabular}

Table 2: The result of variance one-way-analysis between education and domestic violence against women. 
It seems that there is a significant difference among women's educational grades in the rate of domestic violence. In the present research the estate variables of women's education are considered by the degree. And domestic violence variables against women are in the spacious level. The most suitable statistical test to study this relation is Variance one-way-analysis test (the F test). So, in this research, we have used Variance test to examine the relation between women's educational circumstances and domestic violence against them. According to table $3, F=6.256$ with meaningful level of alpha $=0.000$. So, by the information obtained from this research, one can say that there is a significant difference between women's educational degrees and domestic violence rate. As well, the results of regression multivariables analysis show that the variance of the dependent variable due to the independent variables together with educational degrees have been specified about 0.713 of the domestic violence's variance, regarding $\mathrm{R}^{2}$ with the meaningful level of alpha $=0.000$. The analysis findings of multi-variable regression by using multivariable regression, we have dealt with specifying and foreseeing the percent of domestic violence variance, in such analysis by entering the independent variables into multi-variable regression, the variance will be estimated. In table 3 the results of such regression analysis are illustrated.

\begin{tabular}{|c|c|c|c|c|c|}
\hline Variables/Indexed & B & Standard Error & Beta & T Quantity & Meaningful Level \\
\hline Power Structure (patriarchy) in the family & 1.022 & 0.125 & 0.698 & 8.191 & 0 \\
\hline Stereo-typical sexual belief & 0.172 & $0 / 066$ & 0.213 & 2.587 & 0.01 \\
\hline & & & & & \\
\hline Socio-economical position & 0.371 & 0.138 & 0.119 & 2.691 & 0.008 \\
\hline
\end{tabular}

Table 3: Multi-Variable Regression.

The results obtained from $\beta$-ratio show that the power structure in the family, stereotypical sexual belief and socio-economic position variables has had a meaningful effect on domestic violence, to the extent that these three variables concerning $ß$-ratio respectively have had the most effect on the dependent variable.

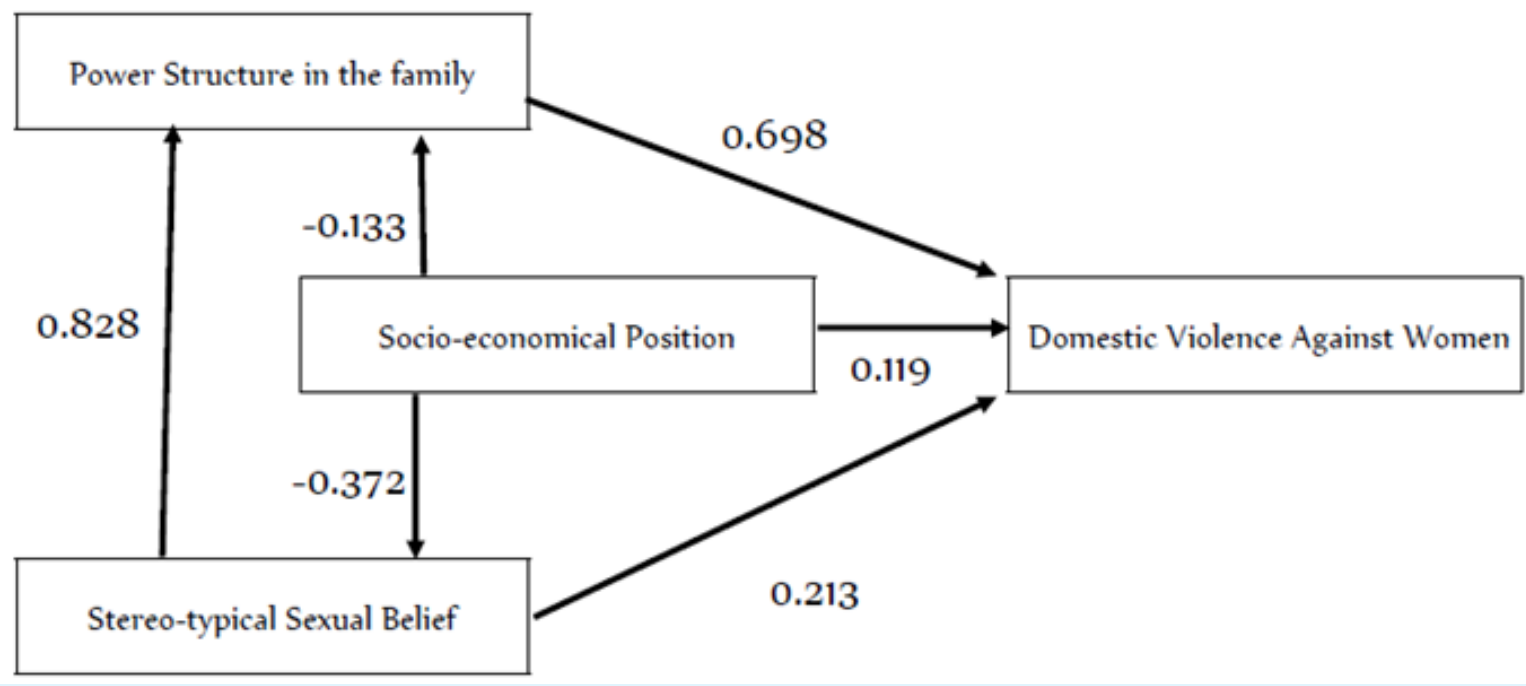

Figure 2: The Conceptual Model of Research. 


\section{Medical Journal of Clinical Trials \& Case Studies}

According to the ratio which was mentioned at the table 3, we can come to the conclusion that power structure in the family is directly effective in making domestic violence clear, and it is regarded as the most important variable that has the most effect on domestic violence with $ß$-ratio of a nearly 0.7 , as such that the stereo-typical sexual belief variable and socio-economical position variable has indirect effect on domestic violence via this variable (power structure in the family). That is to say, when power structure in the family is going toward patriarchy, the women have more intense stereo-typical sexual belief and at the same time they have lower socioeconomical position, and the using of violence will be increased. In addition, it is worthy saying about socioeconomical position that this variable has indirect effect on domestic violence, through stereo-typical sexual belief variable and power structure in the family variable. Thus, the higher the socio-economical position gets, the lower the stereo-typical sexual belief becomes, and the power structure keeps a distance from patriarchy.

\section{Conclusion}

The purpose of this research is to examine the role of power structure in the family and domestic violence against married women in Isfahan. The research findings showed that there is a significant relation between power structure in the family (patriarchy) and domestic violence against women. That is to say, the more asymmetrical the power relation in a family is (going toward patriarchy), the more domestic violence (such as physical, sexual and economical) against the women in that family will be. On the contrary, these two variables are considered as a feminists' contrasting view and feminists believe that the way of distributing of financial resources in a family depends on power relations between husbands and wives. Power relations comes back to the subject that who has the decision-making right of saying where and how the money should be spent [4].

According to feminists' approach, the relation between two genders is based on power relation in whom the man physically, verbally and psychologically abuses his wife. Anyhow, a meaningful relation between socio-economical positions with violence ratio against women is remarkable [5]. That is to say, the higher the socioeconomical position is the lower violence one experiences and on the contrary, as it was mentioned in this theory, when one has lots of resources, he is more likely to use violence. In the present research the hypothesis taken from the resource theory which is approved. There is also a significant difference between women's educational status and domestic violence ratio. This theory has also been taken from resources theory. The power resources which are education, occupation and income, can cause a woman having more power in decision-making. Such resources seem to be an obstacle in the way of the violence which might happen to her.

As well, it becomes clear that the higher the socioeconomical position gets, the more the power structure is drawn to symmetry and advanced toward reasoning. So we come to the conclusion that as the socio-economical position, educational level and income, regarded as two important power resources of symmetrizing the power structure in the family's decision-making, ascend, the power structure goes toward symmetry. This is because the equality approach overcomes and stereo-typical sexual belief fades away. As a result, the findings obtained from this research are in harmony with the results of the researches done by Zare Share Abadi and Amini, Balali Meybodi and Hasani and Eydi, Zanganeh. As well, they are in harmony with many foreign researches like: De Fonsica and others, Haqqi and Faezi, Raj and others, Vioksis and others, Jayupe Kim and Flock and Forste [6-17].

\section{References}

1. Saboori Habib, Mahdavi, Mohammad Sadiq (2003) A Study on the Structure of Power Distribution in the Family. Master's Theses of Shahid Beheshti University, Tehran.

2. Ezazi Sh (2001) Structural Analysis of Sexuality, An Approach over Sexual Analysis in Iran, compiled by Nasrin Jozee. Tehran, Shahid Beheshti University.

3. Bandura A (1977) Social Learning Theory. New York: General Learning Press.

4. Abutte P, Wallace K (1997) Women Sociology (translated by Manizhe Najm Eraqi). Tehran, Ney publications.

5. Shams Esfandabadi, Hassan Emami Pour, Susan (2003) Survey on the Prevalence of Spouse Abuse and Effective Factors. Journal of Women's Research Quarterly 1(5): 82-59.

6. Da Fonseca RMGS, Egry EY, Guedes RN, Gutierres AR, Tezzei FPN (2011) Violence gainst women: a study of the reports to police in the city Itapevi of Sao Paulo, Brazil. Journal of Midwifery 27(4): 469-473. 


\section{Medical Journal of Clinical Trials \& Case Studies}

7. Haqqia S, Faizi A (2010) Prevalence of Domestic Violence and associated Depression in married women at a Tertiary care hospital in Karachi. Procedia Social and Behavioral Sciences 5: 10901097.

8. Raj A, Saggurti N, Lawrence D, Balaiah D, Silverman JG (2010) Association between adolescent marriage and marital violence among young adult women in India. International Journal of Gynecology and Obstetrics 110(1): 35-39.

9. Vives Cases C, Gil-González D, Ruiz-Pérez I, EscribàAgüir V, Plazaola-Castaño J, et al. (2010) Identifying sociodemographic differences in Intimate Partner Violence among immigrant and native women in Spain: A cross-sectional study. Preventive Medicine 51(1): 85-87.

10. Kim JY, Clifton E (2003) Marital Power, Conflict, Norm Consensus, and Marital Violence in a Nationally Representative Sample of Korean Couples. Journal of Interpersonal Violence 18(2): 197-219.

11. Flake D, Forste R (2006) Fighting Families: Family Characteristics Associated with Domestic Violence in Five Latin American Countries. Journal of Family Violence 21(1): 19-29.
12. Azazi, Shahla (2001) Society Structure and Violence against Women. Journal of Social Welfare 14: 11-66.

13. Haj-Yahia M (2000) The Incidence of Wife Abuse and Battering and Some Sociodemographic Correlates as Revealed by Two National Surveys in Palestinian Society. Journal of Family Violence 15(4): 347-374.

14. Jae Yop Kim, Kyu-taik Sung (2000) Conjugal Violence in Korean American Families: A Residue of the Cultural Tradition. Journal of Family Violence 15(4): 331-345.

15. Lambert l, Firestone JM (2000) Economic Context and Multiple Abuse Techniques. Violence against Women 6(1): 49-67.

16. Sorenson SB, Upchurch DM, Shen H (1996) Violence and injury in marital arguments: risk patterns and gender differences. American Journal of Public Health 86(1): 35-40.

17. Stickley A, Kislitsyna O, Timofeeva I, Vågerö D (2008) Attitudes Toward Intimate Partner Violence Against Women in Moscow, Russia. Journal of Family Violence 23(6): 447-456. 